\title{
What's your type: A multidimensional cyclist typology
}

2

\author{
Gabriel Damant-Sirois \\ Graduate Research Assistant \\ School of Urban Planning \\ McGill University \\ Suite 400, 815 Sherbrooke St. W. \\ Montréal, Québec, H3A 2K6 \\ Canada \\ Tel.: 514-398-4058 \\ Fax: 514-398-8376 \\ E-mail: gabriel.damant-sirois@mail.mcgill.ca
}

\author{
Michael Grimsrud \\ Research Fellow \\ Transportation Research at McGill \\ McGill University \\ Suite 400, 815 Sherbrooke St. W. \\ Montréal, Québec, H3A 2K6 \\ Canada \\ Tel.: 514-398-4058 \\ Fax: 514-398-8376 \\ E-mail: michael.grimsrud@mail.mcgill.ca
}

\author{
Ahmed M. El-Geneidy \\ Associate Professor \\ School of Urban Planning \\ McGill University \\ Suite 400, 815 Sherbrooke St. W. \\ Montréal, Québec, H3A 2K6 \\ Canada \\ Tel.: 514-398-8741 \\ Fax: 514-398-8376 \\ E-mail: ahmed.elgeneidy@mcgill.ca
}

\section{March 2014}

\section{Paper accepted for Publication in Transportation}

For citation please use: Damant-Sirois, G., Grimsrud, M., \& El-Geneidy, A. (accepted). What's your type: A multidimensional cyclist typology. Transportation. DOI: 10.1007/s11116-014-9523-8 
1

2

3

4

5

6

\section{ABSTRACT}

Increasing bicycle use for utilitarian trips is a common city objective for health and

environmental improvement and congestion reduction, but cyclists react heterogeneously to interventions and infrastructure. Understanding cyclist types helps in comprehending and planning for this diverse population. This study uses data from 2,004 surveyed Montreal cyclists to generate a multidimensional cyclist typology based on seven factors derived from 35 variables, mostly proven determinants of the intensity of bicycle usage. The analysis revealed four distinct cyclist types: dedicated cyclists, path-using cyclists, fairweather utilitarians, and leisure cyclists. The cycling frequencies of each group respond differently to potential interventions and vary within commuting rate ranges with apparent minima and maxima. Building a network adapted to different cyclist types and emphasizing its convenience, flexibility and speed, could be an effective strategy to increase cycling mode share and frequency among the various groups. Findings from this study can be of benefit to transportation engineers, planners and policy makers as they help in better understanding the impacts of various interventions on the different groups of cyclists.

Keywords: Cyclist typology, Bicycle commuting, Infrastructure preference, Motivation, Factor cluster analysis

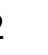

23

4

6

8

0

1

3

4

6


1

\section{1 - INTRODUCTION}

Cycling as a means of transportation has increased in many European and North American metropolitan areas. From what was seen by many as a recreational or physical activity, cycling has also become a mode of transportation to commute in urban areas. Positive impacts of increased bicycle modal share are widely argued, including improved health in the cycling individuals (Gordon-Larsen, Nelson, \& Beam, 2005; Landsberg, Plachta-Danielzik, Much, Johannsen, \& Lange, 2008; Reynolds, Winters, Ries, \& Gouge, 2010), as well as reduced air pollution (Woodcock et al., 2009) and congestion (Banister, Pucher, \& Lee-Gosselin, 2007; Guttenplan, Davis, Steiner, \& Miller, 2007; Woodcock et al., 2009) in the city.

Some research shows that building bicycle infrastructure is expected to increase cycling modal share (Dill \& Carr, 2003). While it is known that safety concerns prevent many people from cycling (Handy \& Xing, 2010), well-designed infrastructure and resulting increased numbers of cyclists both have positive impacts on cyclist safety (Jacobsen, 2003; Wegman, Zhand, \& Dijkstrat, 2012). However, not all cyclists react similarly to the various kinds of infrastructure (Larsen \& El-Geneidy, 2011) or changing conditions (Bergstrom \& Magnusson, 2003; Nankervis, 1999). This fostered a literature of cyclist typologies, based on one or two factors proven to affect cycling behavior like weather conditions (Bergstrom \& Magnusson, 2003), presence of infrastructure(Larsen \& El-Geneidy, 2011), or cycling dedication (Geller, 2006). Furthermore, dividing cyclists into groups rather than analyzing them as a whole population has been proven to give better, more nuanced results (Kroesen \& Handy, 2013).

This study proposes a multidimensional typology drawing from cycling motivations and deterrents, childhood and adulthood encouragement, and preferences about route and infrastructure. These factors represents the proven determinants of bicycle usage such as personal attitudes, social environment and built environment. The typology developed can be used by planners when selecting the types of new infrastructure and by policy makers who are trying to develop policies to encourage cycling in a region. Sections 2 and 3 review of this paper concentrates on the cyclist typology literature and discusses the study context and the data used in our analysis, respectively. Section 4 details our methodology. While section 5 includes the resulting cyclist typology. Section 6 concentrates on the policy implications of the study and presents a new framework for understanding the impact of different interventions on the 
1 frequency of cycling among the four groups. The article ends with section 7 which includes the conclusions and recommendations.

\section{2 - CYCLISTS TYPOLOGY AND CYCLING DETERMINANTS LITERATURE}

5 The goal of this study is to propose a new cyclists' typology built on proven cycling determinants that can be used to guide practitioners in the decision making process. The new typology will provide planners with a better understanding of the impacts of different intervention policies in order to reach cities' objectives of increasing frequency of using a bicycle among existing users. This section presents previous attempts of categorizing cyclists, their approach or methodology, and then, the literature on proven cycling determinants to support the variables chosen to differentiate the sampled population.

\section{1 - Cyclists’ typology}

Previous cyclist typologies or types discriminate based on various factors. One of the first authors to discuss cyclist types is Jensen (1999). He distinguishes three categories each of cyclists and car drivers. Jensen combined cyclists and public transit users, but the types apply logically for bicycle users alone. The cyclists/public transport users of heart cycle for the experience and decide to not own a car. The cyclists/public transport users of convenience cycle because it is the most convenient mode. The cyclists/public transport users of necessity cycle because they cannot afford a car. These categories are useful in order to structure mode selection as a function of choice, whether from principle or utility, or of mode captivity. However, preferences, utility, and constraints likely all influence most cyclists to some degree.

One popular cyclist typology approach uses seasonal criteria. Bergstrom and Magnusson (2003) divided cyclists by frequency and winter usage. Four types were created: winter cyclists, summer-only cyclists, infrequent cyclists and never cyclists. They found that all-year cyclists were more motivated by exercise, summer-only cyclists were negatively impacted by road and weather conditions, and the other two were mainly influenced by travel time.

Gatersleben and Haddad (2010) analyzed the perception of cyclist types among both noncyclists and cyclists. With factor-cluster analysis, they found that individuals' perceptions of cyclists could be categorized into four stereotypes of cyclists. The responsible bicyclist follows traffic rules and is courteous; the lifestyle bicyclist likes cycling and spends a lot of time and money on it; the commuter is a young, well-educated professional who cycles to work regardless 
of weather conditions; and the hippy-go-lucky is considerate and usually female, cycles for all trips purpose, and does not wear bicycle-specific clothes. While this is not a cyclists typology per se but rather a typology of perceived cyclists types, the methodology used in this paper has given good results for this kind of exercise. Unsurprisingly, Gatersleben and Haddad found differences in the identified stereotypes of cyclists between non-cyclist and cyclist respondents. It is well known that attitudes toward cycling impact mode choice (Handy, Cao, \& Mokhtarian, 2005), and such attitudes are likely influenced by perceptions of what cyclists are and how they behave (Daley \& Rissel, 2011), so this stereotype diversity is an interesting finding, but does not address actual cyclist diversity.

A cyclist typology by Larsen and El-Geneidy (2011) might be more useful policy-wise, with findings that frequent cyclists travel farther on average than other groups and that cycling frequency is negatively associated with preference for facilities segregated from street. Their data, however, lacked detail on variables such as peers and institutional encouragement, proven factors of cycling behavior (Cleary \& McClintock, 2000), frequency of utilitarian trips (commute, grocery shopping, other shopping, and restaurant, café and bar) other than commutes, cycling deterrents, and residential location environment.

A now famous cyclists typology has been developed for the city of Portland (Geller, 2006) and has been analyzed recently in another study (Dill \& McNeil, 2013). The typology divides the entire commuting population into four types: No way no how, Interested but concerned, Enthused and confident, and Strong and fearless. The typology divided commuters based primarily on their level of comfort cycling on different infrastructure and street types. Dill and McNeil (2013) tested the typology with the Portland population. Their research shows that it is possible to base bicycle infrastructure recommendations on this kind of exercise, but also shows several limitations to Geller's typology. First, no other type of potential interventions can be recommended using this typology besides bicycle paths, since the typology is based on the comfort of using different infrastructure. Second, the analysis from the survey used in their study gave some strange results when trying to apply the typology. For example, $34 \%$ of the Strong and Fearless end up being classified as non-cyclists, compared to only $23 \%$ and $28 \%$ for Enthused and confident and Interested but concerned, respectively. Also, $10 \%$ of the Interested but concerned group cycle 20-31 days in winter months compared to $0 \%$ of the Strong and fearless group. Planners have used this typology to justify interventions by saying that the 
interested and concerned should be convinced to cycle more, but Dill and McNeil's study (2013) indicates that this group do cycle more than the Strong and fearless. This issue might have arisen because the boxes into which cyclists are supposed to fit have been developed subjectively rather than on an empirical basis: "These numbers, when originally assigned, were not based upon any survey or polling data, or on any study. Rather, they were developed based on the professional experience of one bicycle planner"(Geller, 2006). Such a typology could be refined by increasing the number of factors defining the cyclists and not limiting the study to a predefined framework to allow recommendations on different types of interventions and by building the boxes into which cyclists would fall based on empirical methods rather than a subjective one.

Kroesen and Handy (2013) used two different approaches to test the relation between non-work related trips and commutes. The first approach uses a latent transition model, grouping cyclists into four different clusters: non-cyclists, non-work cyclists, all-around cyclists and commuter cyclists. The other approach was to test the same relation, but keeping cyclists in one group rather than clustering them into four distinct groups. The results from the latent transition model and the conditional change model, which does not differentiate cyclists into clusters, were similar. However, the parameter estimates of each variable varied significantly between the two models and between each group, indicating the importance of a clustering of cyclists approach.

\section{2 - Proven determinants of bicycle usage}

The aim of this paper is to develop a new cyclist typology that incorporates proven cycling determinants, such as cyclists' stated preferences, backgrounds, motivations and deterrents, rather than only behavior or external perceptions. Such determinants and corresponding literature are introduced below.

Weather conditions and effort have been proven to influence bicycle usage significantly (Cleary \& McClintock, 2000; Richardson, 2006). Stinston and Bhat (2004) showed that cyclists who considered cycling as fast and flexible with predictable travel time were more likely to use that mode of transportation, especially for commuting to work. Street design influences travel behavior, especially non-motorized vehicle usage, as car traffic volume and speed, and the proximity to parked cars impact safety perception (Cervero \& Kockelman, 1997). Bicycle facilities and their characteristics such as continuity, physical separation from traffic and signage, have also been shown to influence bicycle usage (Bhat, Sen, \& Eluru, 2009; Handy et al., 2005; Kitamura, Mokhtarian, \& Laidet, 1997). 
The influence of peers, either at school or at work, as well as employers or institutional interventions aimed at increasing cycling commutes has been shown to have a positive impact on bicycle commuting frequencies (Cleary \& McClintock, 2000). In a study that controlled for selfselection (Handy et al., 2005), it was shown that the intensity of bicycle usage was correlated with self-identity as a cyclist and enjoyment while cycling. While the impact of peer pressure and cycling perception during childhood (Underwood \& Handy, 2012) and parental encouragement and bicycle usage for adolescents were recently studied (Emond \& Handy, 2012), in our review we did not find any article generating a link between youth parental encouragement and adult cycling. However studies showed that parental encouragement and parental perception of cycling affect children's travel behavior (Johansson, 2006; Panter, Jones, van Sluijs, \& Griffin, 2010; Tal \& Handy, 2008) and that pre-adult travel behavior affects general behavior such as healthy life habits (Landsberg et al., 2008). In this current study, it is hypothesized that if experience during childhood influences adulthood habits, such as smoking and time spent watching television, it could also affect travel behavior once people become adults.

The aforementioned factors were explored in a survey of Montreal's cyclists aiming to develop an improved and comprehensive typology. The goal of developing such typology is to propose better policy interventions that can help increase cycling mode share and frequency. Improved understanding of the impacts of some interventions on the different types of cyclists can help planners more efficiently and effectively allocate resources. With better understanding of cycling motivations, policy makers can educate populations and inspire bicycle use as a transportation mode. As presented earlier, typologies can be useful to analyze cyclists, but have mostly been developed based on behavior or on perception of what a cyclist is and are one- or two-dimensional. This study integrates multiple proven cycling determinants. Furthermore, instead of behavior or external perceptions, this typology is based on cyclists' stated preferences, backgrounds, motivations and deterrents. The behavioral aspects such as frequency of cycling for utilitarian purposes are then compared between the groups to see if there is significant difference that would justify the approach taken.

\section{3 - STUDY CONTEXT AND DATA}

\section{Study Context}


Montreal is the second largest metropolitan region in Canada, with about 3.9 million inhabitants,

2 the city alone counting about 1.65 million. According to the Canadian census of 2006, Montreal was the Canadian city with the highest combined share of bicycle, walking and public transit commuting (Statistics Canada, 2006). While it is hard to define the bicycle-friendliness of a city,

5 Montreal is considered one of the most convenient North American cities to cycle in with an average Bike Score around 70, ranked $1^{\text {st }}$ among North American cities and $11^{\text {th }}$ in the world in the 2013 Copenhagenize index of bicycle-friendly cities (Copenhagenize Design Co., 2013).

8 Montreal also ranked $3^{\text {rd }}$ in Canada for bicycle commute mode share in 2006 (Statistics Canada, 2006). On the Island of Montreal (the city plus some small municipalities in the region) in 2010, $52 \%$ of the population aged between 18 and 74 years old use a bicycle (Vélo Québec, 2010) and

$1136 \%$ cycled at least once a week.

Bicycle mode share for the Island of Montreal increased by 33\% between 2003 and 2010 and in 2010,3.2\% of the population use a bicycle as their main mode of transportation for commuting (Statistics Canada, 2011). Central boroughs have a higher level of usage than the periphery. For example, $8.6 \%$ of trips in Le Plateau-Mont-Royal use a bicycle compared to $0.5 \%$ in Anjou (see Figure 1) (Vélo Québec, 2010). The bicycle-sharing system BIXI was introduced in 2009 and has experienced a rapid usage increase; in 2009 there were a little over a million single trips made, rising to over four million trips in 2011.

Montreal's geography brings several challenges for cycling. Many people working in the core must cross automobile-dominated bridges connecting the island to the wider region, which can be a barrier. Second, while the city is relatively flat, the downtown area is at the foot of Mount Royal, and some slopes can be quite steep when commuting, especially for people living on the northern side of the mountain. Finally, and more importantly, the winter in Montreal can

24 be relatively harsh with substantial snowfall and cold weather. Cycling drops dramatically during the cold-weather season, although it has seen an increase recently in part due to the implementation in 2008 of the Réseau blanc (white network), a network of bicycle paths

27 receiving snow removal and salting (Figure 1). 


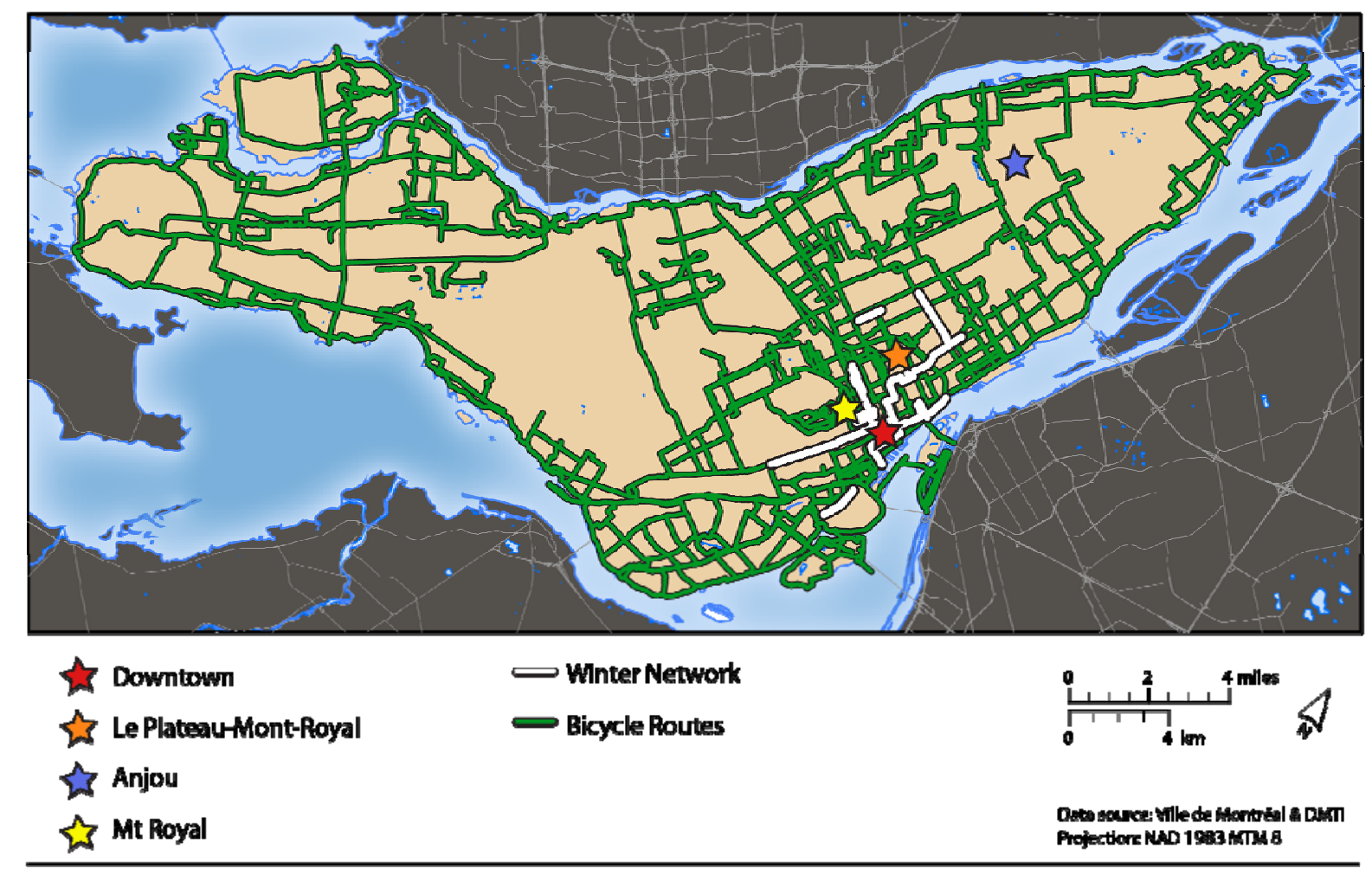

Fig. 1: Montreal cycling infrastructure

\section{Data}

This study uses data from a bilingual online survey of Montreal cyclists prepared by the authors.

The survey was online from the middle of May to the end of June 2013. Following

recommendations of Dillman et al. (2009), extensive efforts to publicize the survey and

minimize sample bias were employed, including: French and English newspaper articles and advertisements; flyer distribution to individuals, bicycle shops, businesses along major bicycle paths, and around a major bicycle event; a major radio show interview; and survey links emailed throughout the Transportation Research at McGill research group mailing list and to different newsletter groups, as well as in social media.

The survey was aimed only at cyclists, but still allowed non-cyclists to answer some questions about why they do not cycle. The first question in the survey asked whether the person has cycled at least once over the past year. Respondents who answered "no" were excluded from our analysis. The total number of respondents was 2,644 , but the final sample used in this research was 2,004 due to some incomplete responses and errors. This resembles the number of home-based cycling trips recorded in the Enquête Origine-Destination (O-D) surveying 5\% of 
the Montreal's region population (Agence Métropolitaine de Transport, 2008), although there are some compositional differences discussed in Section 5.

The survey was divided into seven sections: general information, cycling behavior, cycling history, motivations and habits, infrastructure, route and investment, BIXI (Montreal bicycle-sharing system), and personal profile. Respondents were asked to state their behavior, motivations or deterrents, preferences and personal characteristics in 92 questions with a final open-ended question asking respondents for any further comments. There was no objective measure in the survey of respondents' behavior or observed impact of changing conditions. Survey's participants were asked about general infrastructure preferences like the proximity to traffic and specific infrastructure question like rating types of bike lane and bike path. These two approaches were used to validate the developed clusters' characteristics. The 35 variables used to build the typology along with the survey questions are presented in Table 1 in the following section.

\section{4 - PRELIMINARY ANALYSIS}

This study employs a principal component factor analysis followed by a cluster analysis to classify cyclists and examine differences between cyclist types. This method captures overarching concepts (factors) from groups of multiple, but similar variables, and has been used previously to create a typology of cyclists (Gatersleben \& Haddad, 2010). The same approach was also used in the public transport field to segment the preferences of transit users and nonusers to generate transit market segmentation (Krizek \& El-Geneidy, 2007). The factors or components are obtained by grouping variables of interest based on level of correlation. Once the factors are obtained, clusters of respondents are created by maximizing the mean difference between groups and minimizing it within groups. $\chi^{2}$ tests are then used to compare any significant differences between the groups.

The literature presented earlier about proven cycling determinants is used to choose the variables used in the factor analysis. A total of 35 variables (Table 1) are used to generate seven components. The first component, weather and effort, groups variables related to different weather conditions and factors that can impact effort, both of which have been shown to significantly impact bicycle usage (Cleary \& McClintock, 2000; Richardson, 2006). The second component, time efficiency, is an amalgamation of variables related to speed, flexibility and 
1 predictability of travel time (Stinson \& Bhat, 2004). The third factor, dislike cycling near cars,

2 includes perceived safety impacts based on car volume and speeds as well as proximity to parked

3 cars (Bhat et al., 2009; Cervero \& Kockelman, 1997; Handy et al., 2005; Kitamura et al., 1997).

4 The fourth factor, bicycle route infrastructure, captures perceived importance of path continuity,

5 physical separation, and signage (Dill \& Carr, 2003). The fifth factor, peer and institution

6 encouragement, groups the motivational importance of work or school encouragement and peer

7 cycling behavior (Cleary \& McClintock, 2000). The sixth, cycling identity and enjoyment,

8 groups cycling impacts of self-identity as a cyclist and perception that cycling is fun (Handy et

9 al., 2005). The last factor, parental encouragement, groups separate responses about childhood

10 encouragement from parents to cycle as means of transportation and as a sport or recreational

11 activity (Panter et al., 2010). Table 1 presents the 35 variables and corresponding survey

12 questions used to build the 7 components and their weight in their respective components. 
1 Table 1: Factors, variables, and loadings

\begin{tabular}{|c|c|c|c|}
\hline \multirow{8}{*}{$\begin{array}{l}\text { Factors } \\
\text { Weather and } \\
\text { effort }\end{array}$} & \multicolumn{2}{|l|}{ Variables } & \multirow{2}{*}{$\begin{array}{l}\text { Loading } \\
0.791\end{array}$} \\
\hline & \multirow[t]{7}{*}{ I don't cycle when: } & It's too cold & \\
\hline & & $\begin{array}{l}\text { There is snow because of the } \\
\text { additional effort }\end{array}$ & 0.762 \\
\hline & & $\begin{array}{l}\text { There is ice or snow because } \\
\text { of the risk of slipping }\end{array}$ & 0.712 \\
\hline & & It's raining & 0.702 \\
\hline & & $\begin{array}{l}\text { The route I have to take is too } \\
\text { steep }\end{array}$ & 0.606 \\
\hline & & $\begin{array}{l}\text { I have to carry bags or heavy } \\
\text { loads }\end{array}$ & 0.535 \\
\hline & & It's too hot or humid & 0.531 \\
\hline \multirow[t]{4}{*}{ Time efficiency } & \multirow[t]{4}{*}{$\begin{array}{l}\text { How important are those factors in your } \\
\text { decision to cycle now: }\end{array}$} & $\begin{array}{l}\text { Flexibility of my departure } \\
\text { time? }\end{array}$ & 0.879 \\
\hline & & Flexibility for multiple trips? & 0.872 \\
\hline & & $\begin{array}{l}\text { It's the fastest way to get from } \\
\text { A to B? }\end{array}$ & 0.819 \\
\hline & & Predictability of travel time? & 0.812 \\
\hline \multirow{3}{*}{$\begin{array}{l}\text { Dislike cycling } \\
\text { near cars }\end{array}$} & \multirow{3}{*}{$\begin{array}{l}\text { How important are the following factors } \\
\text { in making a good bicycle route: }\end{array}$} & Low number of cars driving? & 0.871 \\
\hline & & Low speed of cars? & 0.798 \\
\hline & & Low number of parked cars? & 0.557 \\
\hline \multirow{3}{*}{$\begin{array}{l}\text { Bicycle route } \\
\text { infrastructure }\end{array}$} & \multirow{3}{*}{$\begin{array}{l}\text { How important are the following factors } \\
\text { in making a good bicycle route: }\end{array}$} & Continuous bicycle route? & 0.787 \\
\hline & & $\begin{array}{l}\text { Presence of a bicycle path } \\
\text { with a physical barrier? }\end{array}$ & 0.711 \\
\hline & & Bicycle-specific signage? & 0.689 \\
\hline \multirow{2}{*}{$\begin{array}{l}\text { Peer and } \\
\text { institution } \\
\text { encouragement }\end{array}$} & \multirow[t]{2}{*}{$\begin{array}{l}\text { How important are those factors in your } \\
\text { decision to cycle now: }\end{array}$} & $\begin{array}{l}\text { My employer / school } \\
\text { encourages cycling? }\end{array}$ & 0.879 \\
\hline & & $\begin{array}{l}\text { My classmates / coworkers } \\
\text { cycle? }\end{array}$ & 0.870 \\
\hline \multirow[t]{2}{*}{$\begin{array}{l}\text { Cycling identity } \\
\text { and enjoyment }\end{array}$} & \multirow[t]{2}{*}{$\begin{array}{l}\text { How important are those factors in your } \\
\text { decision to cycle now: }\end{array}$} & $\begin{array}{l}\text { It's part of my self- } \\
\text { identity/culture? }\end{array}$ & 0.803 \\
\hline & & Cycling is fun? & 0.753 \\
\hline \multirow[t]{3}{*}{$\begin{array}{l}\text { Parental } \\
\text { encouragement }\end{array}$} & \multirow[t]{2}{*}{$\begin{array}{l}\text { To what extent your parent(s) or } \\
\text { guardian(s) encouraged you to cycle: }\end{array}$} & $\begin{array}{l}\text { As a way to reach } \\
\text { destinations? }\end{array}$ & 0.823 \\
\hline & & $\begin{array}{l}\text { As a sport or recreational } \\
\text { activity? }\end{array}$ & 0.799 \\
\hline & Did you start cycling as a child? & Yes or no & 0.435 \\
\hline
\end{tabular}




\section{5 - RESULTS}

\section{Cyclist Typology}

3 Previous typologies of cyclists, as presented earlier, were usually one- or two-dimensional:

4 winter cycling or not, frequency and bicycle paths usage, or motivations to cycle. Gatersleben

5 and Haddad (2010) examined stereotypes of what a cyclist is. The typology built here is

6 multidimensional (external conditions, motivations, infrastructure, personal identity toward

7 cycling and past cycling history) and focuses on cyclists' characterizations of themselves rather

8 than largely external attributions like in the Gatersleben and Haddad (2010) article. It analyzes

9 the data initially at the disaggregate level, by making cyclists define themselves, rather than imposing an image of what cyclists are.

Using the factors from the abovementioned principle component analysis, K-means clustering was performed. The clustering was tried with three to eight groups, but the best results were obtained with four clusters, as is common in the literature (Jacques, Manaugh, \& Elutilitarians and leisure cyclists (Figure 2).

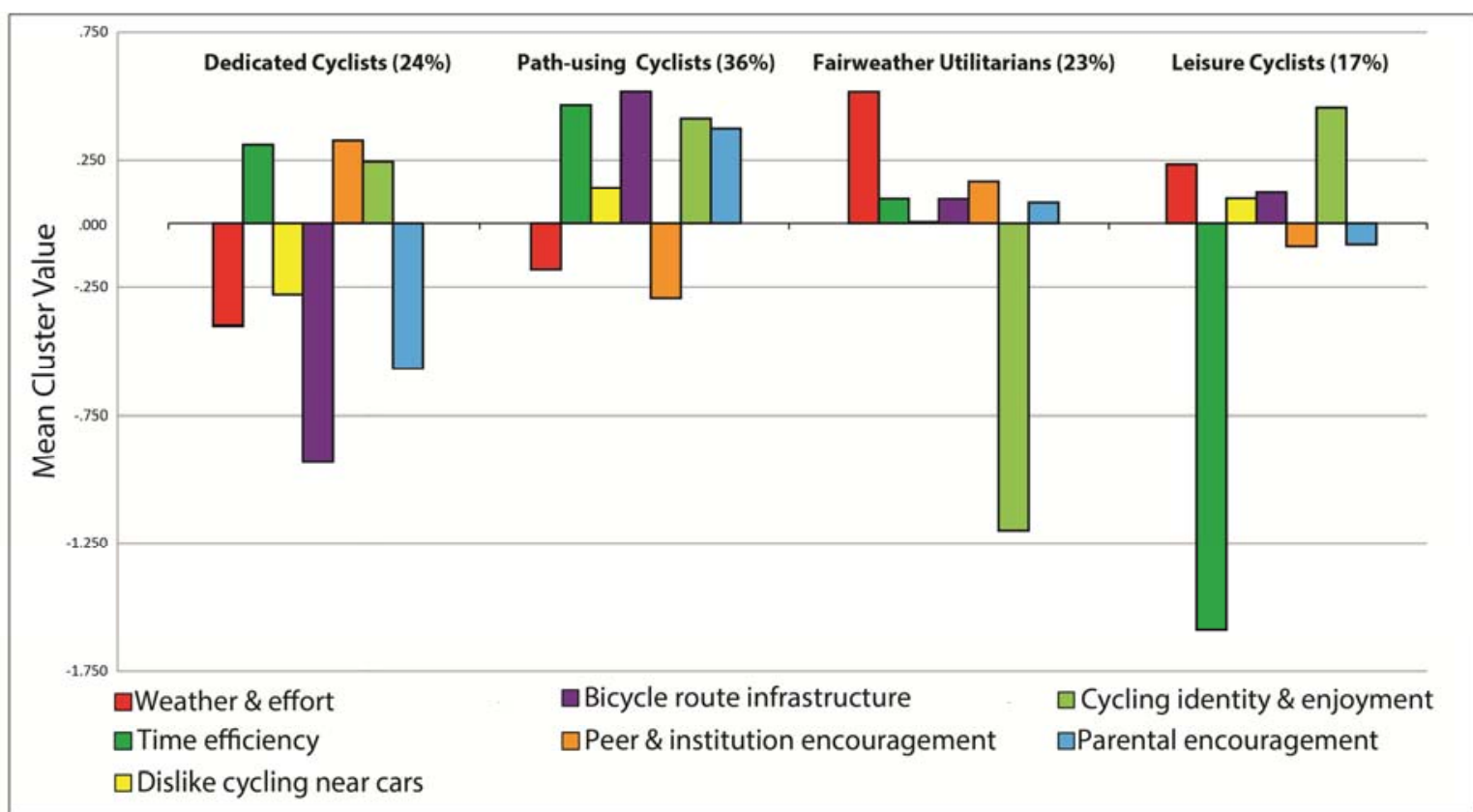


1

\section{Dedicated Cyclists}

Dedicated cyclists' (24\% of the sample) decision to use a bicycle is not strongly impacted by the weather conditions. The speed, predictability, and flexibility of bicycle trips motivate cyclists in this group to cycle. Peer and employer/school encouragement are also key factors influencing this group. They also see themselves as cyclists and enjoy using a bicycle. They are less keen on bicycle-specific infrastructure than are other groups and do not mind, and sometimes even prefer, riding in car traffic, as shown by a participant's comment answering the open-ended question at the end of the survey: "I find bike paths more dangerous than busy city streets with cars". They are also defined by not having received parental encouragement to cycle as children.

\section{Path-Using Cyclists}

Path-using cyclists (36\% of the sample) are only slightly more affected by weather than are dedicated cyclists. Their main motivations to cycle are convenience and fun, as well as their identity as a cyclist. They prefer to use a continuous bicycle route that is separated from car traffic by a physical barrier with specific signalization, which is explained by the fact that they dislike cycling near moving and parked cars as shown by this comment in French, followed by the authors' translation: “Les cyclistes souhaitent-ils circuler dans des rues également utilisées par des véhicules motorisés? Réponse : Non, ils souhaitent circuler dans des rues dédiées aux cyclistes $[. .]$.$» (Do cyclists wish to circulate in streets used by motorized vehicles? The answer$ is no, they want to circulate in streets dedicated to cyclists). They were actively encouraged by their parents to use bicycles both to reach destinations and for sport or recreational activity.

\section{Fairweather Utilitarians}

Fairweather utilitarians (23\% of the sample) are contextual users. They do not cycle in bad weather, and will choose another mode if it is more convenient. They prefer to cycle on bicycle paths and can be motivated by peers or institutional encouragement. This group is uniquely populated, and largely defined, by members who might not consider themselves cyclists, as shown by a comment from a survey respondent: "Le plus grand obstacle au cyclisme sont les cyclistes eux-même” (The biggest barrier to cycling is the cyclists themselves). 
2 Leisure Cyclists

3 Leisure cyclists (17\% of the sample) do not cycle because it is a fast, convenient mode, but

4 because they enjoy it and identify as cyclists. Their decision to use a bicycle is influenced by

5 weather conditions, and they prefer not to ride close to cars and prefer to use bicycle

6 infrastructure segregated from traffic: "Pour les enfants et familles, avoir un réseau cyclable

7 développé est très important (pistes cyclable séparée [sic]) car sentiment de sécurité". (For

8 children and families, a well-developed cycling network is very important [segregated bicycle

9 paths], in order to feel safe). This type groups cyclists that mostly cycle as a hobby or as a family 10 activity.

12 Further Differentiation

13 Demographic characteristics of each group help refine definitions, with significant differences

14 between some of them. This sample differs notably from the cyclist population who participated

15 in the 2008 Montreal origin-destination survey (Table 2). The sample has more females (40\% vs.

$1635 \%$ ), is younger (average age of 37 compared to 42), has a slightly smaller household size, has

17 more full-time employees and students, and is wealthier. However, the O-D survey was done in

18 2008, and cycling has increased substantially in recent years in Montreal (Vélo Québec, 2010),

19 perhaps in part due to the introduction of Bixi and the importance given to cycling in the 2008

20 Montreal Transportation Plan (Ville de Montréal, 2008). Furthermore, a 2012 Montreal cycling

21 survey focused on bicycle theft showed demographic characteristics similar to those here (van

22 Lierop, Grimsrud, \& El-Geneidy, 2013). 
Table 2: Demographic characteristics

\begin{tabular}{|c|c|c|c|c|c|c|c|}
\hline & \multirow[t]{2}{*}{$\begin{array}{l}\text { All survey } \\
\text { respondents }\end{array}$} & \multirow[t]{2}{*}{$\begin{array}{l}\text { Path-using } \\
\text { Cyclists }\end{array}$} & \multirow[t]{2}{*}{$\begin{array}{l}\text { Dedicated } \\
\text { Cyclists }\end{array}$} & \multirow[t]{2}{*}{$\begin{array}{l}\text { Fairweather } \\
\text { Utilitarians }\end{array}$} & \multirow[t]{2}{*}{$\begin{array}{l}\text { Leisure } \\
\text { Cyclists }\end{array}$} & \multicolumn{2}{|c|}{$\begin{array}{l}2008 \text { Origin- } \\
\text { Destination Survey }\end{array}$} \\
\hline & & & & & & Cyclists & All \\
\hline \multicolumn{8}{|l|}{ Gender } \\
\hline Female & $40 \%$ & $42 \%$ & $42 \%$ & $41 \%$ & $31 \%$ & $35 \%$ & $53 \%$ \\
\hline Male & $59 \%$ & $57 \%$ & $56 \%$ & $57 \%$ & $68 \%$ & $65 \%$ & $47 \%$ \\
\hline \multicolumn{8}{|l|}{ Age } \\
\hline Average & 37.32 & 36.15 & 36.33 & 35.84 & 43.46 & 42 & 48 \\
\hline $18-30$ & $34 \%$ & $38 \%$ & $35 \%$ & $38 \%$ & $16 \%$ & $24 \%$ & $16 \%$ \\
\hline $31-40$ & $34 \%$ & $33 \%$ & $38 \%$ & $35 \%$ & $28 \%$ & $22 \%$ & $16 \%$ \\
\hline $41-50$ & $17 \%$ & $16 \%$ & $14 \%$ & $15 \%$ & $26 \%$ & $25 \%$ & $21 \%$ \\
\hline $51-60$ & $11 \%$ & $9 \%$ & $9 \%$ & $9 \%$ & $20 \%$ & $24 \%$ & $28 \%$ \\
\hline $61+$ & $4 \%$ & $3 \%$ & $4 \%$ & $3 \%$ & $9 \%$ & $6 \%$ & $19 \%$ \\
\hline \multicolumn{8}{|l|}{ Household size } \\
\hline 1 & $20 \%$ & $24 \%$ & $20 \%$ & $22 \%$ & $17 \%$ & $22 \%$ & $15 \%$ \\
\hline 2 & $41 \%$ & $40 \%$ & $42 \%$ & $41 \%$ & $46 \%$ & $34 \%$ & $38 \%$ \\
\hline 3 & $18 \%$ & $15 \%$ & $17 \%$ & $18 \%$ & $18 \%$ & $20 \%$ & $19 \%$ \\
\hline 4 & $15 \%$ & $14 \%$ & $14 \%$ & $14 \%$ & $14 \%$ & $17 \%$ & $19 \%$ \\
\hline $5+$ & $6 \%$ & $6 \%$ & $4 \%$ & $5 \%$ & $7 \%$ & $7 \%$ & $9 \%$ \\
\hline \multicolumn{8}{|l|}{ Occupation } \\
\hline Employed Full-time & $64 \%$ & $60 \%$ & $63 \%$ & $64 \%$ & $73 \%$ & $59 \%$ & $52 \%$ \\
\hline $\begin{array}{l}\text { Employed Part- } \\
\text { time }\end{array}$ & $8 \%$ & $9 \%$ & $15 \%$ & $7 \%$ & $6 \%$ & $9 \%$ & $6 \%$ \\
\hline Student & $17 \%$ & $20 \%$ & $18 \%$ & $21 \%$ & $8 \%$ & $13 \%$ & $8 \%$ \\
\hline Retired & $3 \%$ & $2 \%$ & $2 \%$ & $2 \%$ & $1 \%$ & $11 \%$ & $25 \%$ \\
\hline Unemployed & $1 \%$ & $2 \%$ & $2 \%$ & $1 \%$ & $1 \%$ & $8 \%$ & $10 \%$ \\
\hline \multicolumn{8}{|l|}{ Household Income } \\
\hline$<\$ 20,000$ & $13 \%$ & $18 \%$ & $13 \%$ & $11 \%$ & $6 \%$ & $15 \%$ & $12 \%$ \\
\hline$\$ 20,000-\$ 40,000$ & $16 \%$ & $17 \%$ & $19 \%$ & $15 \%$ & $8 \%$ & $24 \%$ & $22 \%$ \\
\hline$\$ 40,000-\$ 60,000$ & $16 \%$ & $17 \%$ & $17 \%$ & $16 \%$ & $10 \%$ & $22 \%$ & $21 \%$ \\
\hline$\$ 60,000-\$ 80,000$ & $11 \%$ & $10 \%$ & $11 \%$ & $13 \%$ & $13 \%$ & $16 \%$ & $16 \%$ \\
\hline$\$ 80,000-\$ 100,000$ & $11 \%$ & $11 \%$ & $8 \%$ & $11 \%$ & $13 \%$ & $10 \%$ & $11 \%$ \\
\hline$>\$ 100,000$ & $24 \%$ & $18 \%$ & $22 \%$ & $23 \%$ & $40 \%$ & $13 \%$ & $17 \%$ \\
\hline
\end{tabular}

7 higher than the sample. They are six years older on average and have much higher incomes, 
1 possibly explained by the proportion of students being less than half that of the other groups.

2 Leisure cyclists also own one or more cars $44 \%$ more frequently than average and car ownership

3 has been proven to be an important factor in modal choice (Lee, Nam, \& Lee, 2012). The general

4 demographic characteristic similarity between the other three groups is supporting the exclusion

5 of these variables in the principal component analysis.

Motivations to cycle, transportation behavior and preferences not included in the factor cluster analysis do differ significantly between groups, and these contrasts are important because convincing people to cycle or cycle more requires understanding their motivations, and locating and building adequate infrastructure requires understanding behavior and preferences. Figure 3 (a) illustrates the proportion of cyclists of each type who indicated a factor is important or very important to their decision to cycle. Environmental reasons motivate almost universally, especially among path-using cyclists but less so for leisure cyclists. Health also motivates all cyclist groups, especially leisure cyclists and path-using cyclists. The importance that is placed on the low cost of cycling varies substantially between groups, and was found to be far more important for path-using cyclists (79\%) than leisure cyclists (46\%), corresponding inversely and unsurprisingly to the groups' household incomes. Directness to destination, as expected, is more important for the groups that were also positively correlated to the time efficiency factor.

A

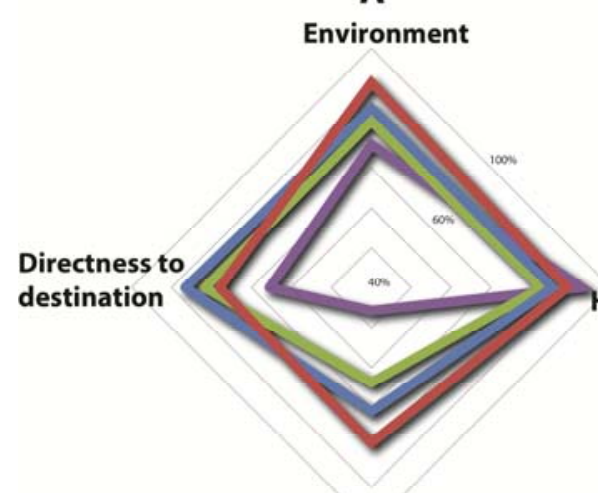

Cheap cost of cycling

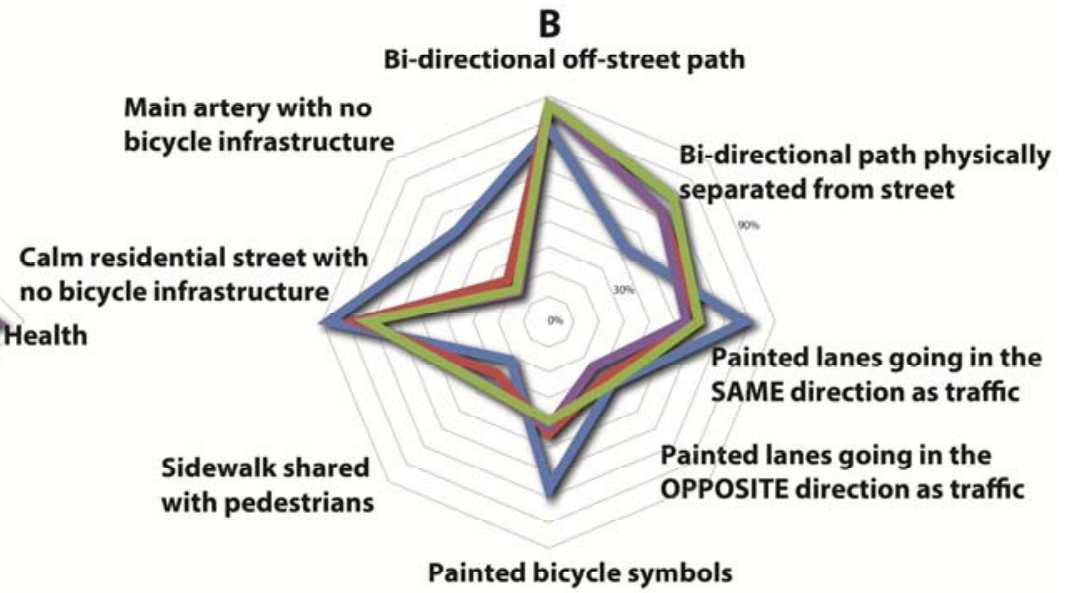

Painted bicycle symbols 
1 traffic. The differences come mostly from the dedicated cyclists who, compared to the other

2 groups, enjoy unsegregated route types like residential streets, painted lanes, markings on the

3 pavement, or even riding mixed with traffic on main arteries. This is not surprising as the

$4 \quad$ dedicated cyclists were defined largely by their relative indifference to nearby cars and physical

5 separation from traffic.

Substantial inter-group difference is seen in the distances between home and job/school

7 location: $71 \%$ of the leisure cyclists live farther from work/school than the sample median

8 distance. Some evidence suggests behaviors or preferences influence the choice of home

9 location, rather than the reverse. Answering why they moved to their current home location, the

10 share of Leisure cyclists for whom having a "spacious home" was very important was about 1.5

11 times more than that of the sample average, living in a "calm neighborhood" was 1.42 times

12 more, and "proximity to shopping and services" was 1.29 times lower. Interestingly, "proximity

13 to bicycle infrastructure" was about 1.40 times less important for dedicated cyclists and

14 fairweather utilitarians than for the sample average, perhaps due to traffic indifference in the

15 first case and to perceived infrequent cycling in the second.

The stated frequency of cycling for utilitarian purposes of each group presents an

17 interesting pattern (Figure 4). Leisure cyclists peak at "rarely", fairweather utilitarians at

18 "sometimes", and path-using cyclists and dedicated cyclists at "often", the latter two groups with over $20 \%$ of members "always" cycling. The least cycled trip purpose for all groups is grocery shopping, followed by other shopping. Many respondents, especially outside of dedicated

21 cyclists, seem as though they might have answered "always" if not for winter conditions. Indeed, $2282 \%$ of respondents agreed or strongly agreed that they do not cycle when there is ice on the 23 pavement (even $69 \%$ for dedicated cyclists), which is by far the most commonly reported factor 24 preventing all cyclists from cycling in Montreal, (48\% snow, $46 \%$ cold, $36 \%$ rain, and $9 \%$ heat 25 and humidity). 


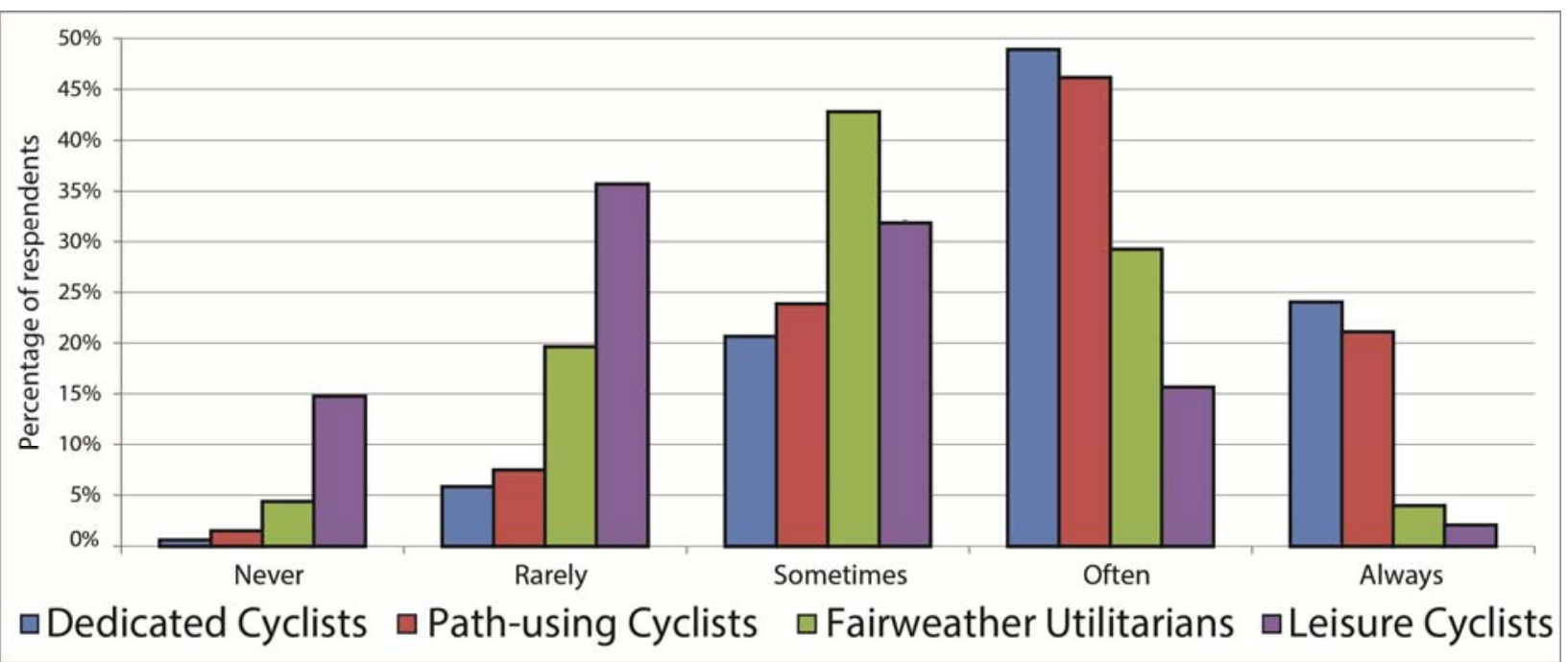

\section{Fig. 4: Frequency of cycling for utilitarian purpose}

\section{Impact of motivators on frequency of cycling for utilitarian purposes}

Analyzing other variables allows examination of the potential effectiveness of bicycle promotion based on different motivators. As shown by looking at the literature on active transportation, one of the most promoted positive impacts of cycling is health through exercise. The data collected shows health benefits motivate all cyclist groups, and many comments note having picked up cycling for health reasons. However, a $\chi^{2}$ test on the relation between frequency of utilitarian trips and health motivation shows no significance, except a negative one with frequency of trips to restaurant, café and bar ( $\mathrm{p}<0.01)$. Also, the group that is motivated the most by health, the leisure cyclists, cycles the least often for utilitarian purposes and commuting. Therefore, promoting health as a reason to cycle can inspire people to try cycling, but does not seem likely to increase frequency among current cyclists.

Speed motivation strongly correlates with use frequency, $68 \%$ of people who always cycle to work or school indicating that speed is a very important cycling motivator. Health is a very important reason to cycle for $44 \%$ of those who always cycle to work or school, but also for $43 \%$ of those who never do so. Speed was unimportant or very unimportant for only $1.5 \%$ of people who always commute by bicycle. Of those for whom health was a very unimportant motivator, $77 \%$ often or always cycle to work or school. Measures of convenience such as flexibility for multiple trips, predictability of travel time and flexibility of departure time relate to cycling frequency largely the same as does speed. Therefore, if a city or government intends to increase bicycle modal share, promoting the convenience of cycling might be more effective, 
especially considering that travel time is a major mode choice determinant (van Exel \& Rietveld, 2010). This is particularly true in cities where populations are already aware of cycling and many individuals do it occasionally, such as Montreal where $52 \%$ of adults in the city cycled at least once in 2010 (Vélo Québec, 2010). Promoting cycling as an exercise activity could even possibly deter some people from commuting as it may encourage a perception that high levels of effort are required. The data shows that to increase the frequency of cycle commutes, emphasizing the convenience and speed of cycling should be more effective.

In this study, the parental encouragement of childhood cycling did not show an impact on adulthood utilitarian cycling frequency $(\mathrm{p}=0.140)$. It contrasts, but not contradicts findings from Emond and Handy (2012) that found a positive correlation between parental encouragement and usage of bicycle to commute to school for teens. However, it helps distinguish the two groups that cycle the most, path-using cyclists and dedicated cyclists. The data and analysis in this study do not allow definitive conclusions on impacts of childhood parental encouragement to be drawn, but note a possible direction for future research. Interestingly, the most parentallyencouraged group uses segregated bicycle infrastructure the most, while the least parentallyencouraged uses it the least. It might come from parents who encouraged their children to cycle also asking them to use certain route types or cycling with them on paths and creating habits. There is a significant positive relationship $(\mathrm{p}<0.05)$ between frequency of parents' utilitarian trips and encouraging their children to cycle. Also, those in the two groups that cycle the most for utilitarian purposes encourage their children significantly $(p<0.01)$ more than other group members, especially to reach destinations (not as a sport or recreational activity). This might suggest that a virtuous circle could start, or already exists, with increased adult cycling.

\section{6 - DISCUSSION}

Different strategies are needed to facilitate increases in cycling among different groups of people (Panter et al., 2010). Cyclists are heterogeneous, but with some similar characteristics that allow clustering. This study generated a typology based on stated cycling motivations and deterrents, childhood and adulthood encouragement, and general infrastructure preferences. It shows meaningful differences between groups in demographic characteristics, behavior and specific infrastructure preferences. Analyzing answers about motivators, deterrents, and infrastructure preferences given by respondents of each cyclist type allows understanding which type of 
cyclists will likely be affected by certain interventions. Also, looking at commuting frequency per type of cyclist allows determination of approximate bicycle commute frequency minima and maxima for each group. Figure 5 shows in a simplified way each group's relevant intervention areas and range of frequently observed commuting frequencies.

\section{Interventions}

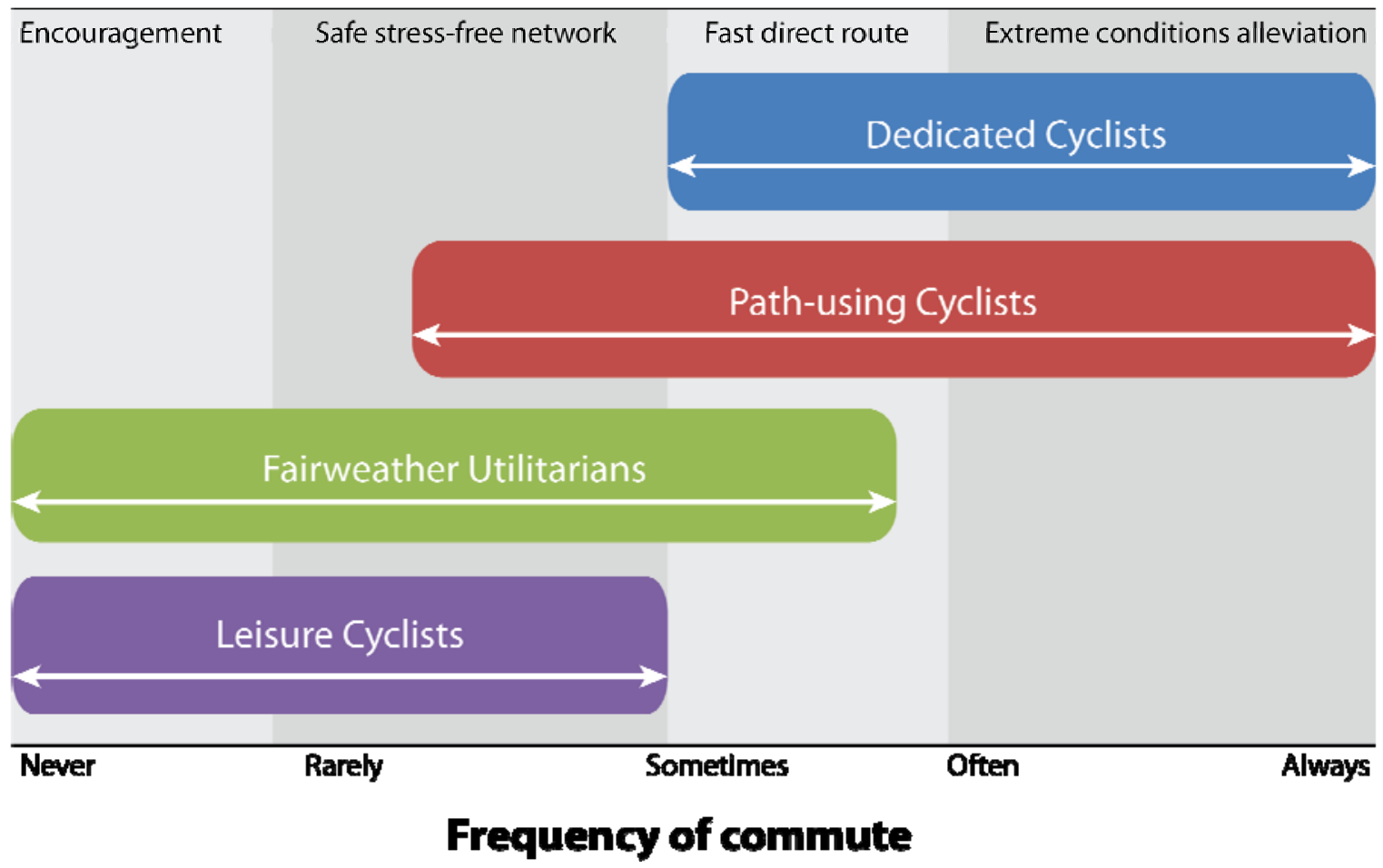

Fig. 5: Cyclist types, commute frequencies, and relevant intervention areas

In the survey, encouragement could come from initiatives by school or work to incite students or workers to use their bicycle to commute or from an educational campaign aimed at cyclists or other road users. For example, encouragement can come from an employer installing shower facilities or providing employees with free bicycle-sharing memberships, and can also be the result of public awareness campaigns on cycling safety, convenience and benefits.

Encouragement is an important step to convince people who are contemplating bicycle commuting to make them aware that getting on a bicycle is a viable option (Nkurunziza, Zuidgeest, \& Van Maarseveen, 2012). It could also push a non-cyclist or non-commuting cyclist to try using a bicycle to commute to work or school. Leisure cyclists and fairweather utilitarians are the two groups that could be the most influenced by encouragement. The safe stress-free network might feature segregated facilities along important commute routes accompanied by 
safe and potentially secured bicycle parking. This would help a person that already cycles sporadically to feel more comfortable and incite them to use a bicycle more frequently than they currently do. Recreational cyclists with expensive bicycles might also cycle to work if not worried about bicycle theft. Bicycle usage frequencies of leisure cyclists, fairweather utilitarians and path-using cyclists are likely to be positively impacted by enhancing the safe stress-free network. This is especially true for the path-using cyclists, who value segregated infrastructure the most.

Numerous streets with bicycle lanes, bicycle markings and signage aimed at increasing the awareness of the presence of cyclists can contribute to fast direct routes complementary to the segregated ones. These infrastructure changes require smaller investment than segregated paths, often requiring only a small amount of space, and are easy to build on most streets. Fast direct routes reduce travel time and increase convenience for cyclists who are already comfortable cycling in urban environments, thereby improving the attractiveness of cycling in comparison to other modes. Fairweather utilitarians, path-using cyclists and dedicated cyclists could increase their bicycle commuting if such measures would be put in place, as time efficiency motivates them the most. Alleviating extreme conditions that at times substantially interfere with cycling, like plowing away Montreal winter snow, can keep some cyclists choosing to ride through conditions that would otherwise dissuade them. . Only path-using cyclists and dedicated cyclists could be significantly affected by such measures. The other two types already refrain from cycling in even less severe weather conditions.

The questions in the survey were purposefully aimed at being generalizable to other regions and not only to the particular bicycle culture of Montreal. While Montreal has a strong bicycle culture compared most North American cities, the variables used in the clustering of cyclists have been found to be determinants of bicycle usage around the world. The percentage of each group among the cyclist population will differ in other regions, but similar groups of cyclists are expected to be present.

\section{7 - CONCLUSION}

The main goal of this research was to build a useful multidimensional cyclist typology. The four resulting groups are strongly distinct from each other and are likely to react differently to efforts to increase cycling in a city. The last point is important because with limited funds and polarized 
political positions on public investment in cycling infrastructure, every dollar spent should produce results. The four clusters were defined by the motivations and deterrents to cycle, childhood and adulthood encouragement, and route and infrastructure preferences. Each factor has been shown to affect bicycle usage intensity in previous research except childhood encouragement, apparently untested before now. While not proven to relate to utilitarian trip frequency, it seems to relate to cycling behavior or preferences, and further studies might explore this theme.

Finally, different strategies apply to different types of cyclists. Some interventions such as segregated paths and regular de-icing would likely increase cycling substantially for some groups but not all, and some groups are unlikely to cycle beyond a certain threshold regardless of investments. Health benefits have been promoted to increase cycling. This seems to be effective to encourage first-time or resuming cyclists, but there is no significant relationship between health motivation and cycling frequency for utilitarian trips. Speed and convenience strongly and positively relate to cycling frequency and have been proven to influence modal choice in other studies. To increase bicycle modal share, the attractiveness of cycling should be increased relative to other modes. This paper helps do so, showing to planners and decision makers a useful portrayal of a heterogeneous cyclist population by dividing it into types and showing interventions that would motivate each type to commute by bicycle more often.

\section{ACKNOWLEDGEMENT}

This research was funded through National Sciences in Engineering Research Council of Canada (NSERC) Discovery program. The authors would like to thank Daniel Schwartz for helping with survey-related technical issues, and Évelyne St-Louis for survey translation. We are also grateful to the Coalition Vélo Montréal for input on Montreal bicycle issues and all to the Montreal cyclists who filled out the survey and wrote insightful and sometimes extensive comments. Thanks to Mr. Daniel Bergeron from Agence Métropolitaine de Transport for providing the ODsurevy data used in the comparisons. Thanks to Kevin Manaugh and Dea van Lierop as well as all the Transportation Research at McGill (TRAM) research group members for their support during survey preparation and data collection and their useful analysis insights. Last but not least we would like to that the four anonymous reviewers for their great feedback on the earlier versions of the manuscript. 


\section{REFERENCES}

Agence Métropolitaine de Transport. (2008). Enquête Origine-Destination. Région Métropolitaine de Montréal.

Banister, D., Pucher, J., \& Lee-Gosselin, M. (2007). Making sustainable transport politically and publicly acceptableL Lessons from the EU, USA and Canada. In P. Rietveld \& R. Stough (Eds.), Institutions and Sustainable Transport: Regulatory Reform in Advanced Economies (pp. 17-50). Cheltenham: Edward Edgar Publishing.

Bergstrom, A., \& Magnusson, R. (2003). Potential of transferring car trips to bicycle during winter. Transportation Research Part A: Policy and Practice, 37(8), 649-666.

Bhat, C., Sen, S., \& Eluru, N. (2009). The impact of demographics, built environement attributes vehicle characteristics, and gasoline prices on household vehicle holding and use. Transportation Research Part B: Methodological, 43(1), 1-18.

Cervero, R., \& Kockelman, K. (1997). Travel demand and the 3Ds: density, diversity, and design Transportation Research Part D: Transport and Environment, 2(3), 199-219.

Cleary, J., \& McClintock, H. (2000). The Nottingham cycle-friendly employers project: Lessons for encouraging cycle commuting. Local Environment, 5(2), 217-222. doi: 10.1080/13549830050009364

Copenhagenize Design Co. (Producer). (2013). The Copenhagenize index 2013: Bicycle friendly cities.

Daley, M., \& Rissel, C. (2011). Perspectives and images of cycling as a barrier or facilitator of cycling. Transport Policy, 18(1), 211-216. doi: http://dx.doi.org/10.1016/j.tranpol.2010.08.004

Dill, J., \& Carr, T. (2003). Bicycle commuting and facilities in major U.S. cities: If you build them, commuters will use them. Transportation Research Record, 1828, 116-123.

Dill, J., \& McNeil, N. (2013). Four types of cyclists? Examining a typology to better understand bicycling behavior and potential. Paper presented at the Transportation Research Board Annual Meeting, Washington DC.

Dillman, D., Smyth, J., \& Christian, L. (2009). Internet, mail and mixed-mode surveys: The tailored design method, third edition. Hoboken, NJ: John Wiley and Sons, Inc.

Emond, C. R., \& Handy, S. L. (2012). Factors associated with bicycling to high school: insights from Davis, CA. Journal of Transport Geography, 20(1), 71-79.

Gatersleben, B., \& Haddad, H. (2010). Who is the typical bicyclist? Transportation Research Part F: Traffic Psychology and Behaviour, 13(1), 41-48.

Geller, R. (2006). Four types of cyclists. Portland, OR: Retrieved from http://www.portlandoregon.gov/transportation/article/264746.

Gordon-Larsen, P., Nelson, M., \& Beam, K. (2005). Associations among active transportation, physical activity, and weights status in young adults. Diet and Physical Activity, 13(5), 868-875.

Guttenplan, M., Davis, B., Steiner, R., \& Miller, D. (2007). Planning-level areawide multimodal level-of-service analysis: Performance measures for congestion management. Transportation Research Record, 1858(2003), 61-68.

Handy, S., Cao, X., \& Mokhtarian, P. (2005). Correlation or causality between the built environment and travel Behavior? Evidence from Northern California. Transportation Research Part D: Transport and Environment, 10(6), 427-444. 
Handy, S., \& Xing, Y. (2010). Factors correlated with bicycle commuting: A study in six small U.S. cities. International Journal of Sustainable Transportation, 5(2), 91-110. doi: 10.1080/15568310903514789

Jacobsen, P. (2003). Safety in numbers: More walkers and bicyclists, safer walking and bicycling. Injury Prevention, 9(3), 205-209. doi: 10.1136/ip.9.3.205

Jacques, C., Manaugh, K., \& El-Geneidy, A. (2012). Rescuing the captive [mode] user: An alternative approach to transport market segragation. Transportation, 40(3), 625-645.

Jensen, M. (1999). Passion and hearth in transport - a Sociological analysis on transport behaviour. Transport Policy, 6, 19-33.

Johansson, M. (2006). Environment and parental factors as determinants of mode for children's leisure travel. Journal of Environmental Psychology, 26(2), 156-169. doi: http://dx.doi.org/10.1016/j.jenvp.2006.05.005

Kitamura, R., Mokhtarian, P., \& Laidet, L. (1997). A micro-analysis of land use and travel in five neighborhoods in San Francisco Bay area. Transportation, 24(2), 125-158.

Krizek, K., \& El-Geneidy, A. (2007). Segmenting preferences and habits of transit users and non-users. Journal of Public Transportation, 10(3), 71-94.

Kroesen, M., \& Handy, S. (2013). The relation between bicycle commuting and non-work cycling: results from a mobility panel. Transportation, 1-21. doi: 10.1007/s11116-0139491-4

Landsberg, B., Plachta-Danielzik, S., Much, D., Johannsen, M., \& Lange, D. (2008). Association between active commuting to school, fat mass and lifestyle factors in adolescents: the Kiel Obesity Prevention Study (KOPS). European Journal of Clinical Nutrition, 62, 739747.

Larsen, J., \& El-Geneidy, A. (2011). A travel behavior analysis of urban cycling facilities in Montreal Canada. Transportation Research Part D: Transport and Environment, 16(2), 172-177.

Lee, J., Nam, J., \& Lee, S. (2012). Built environment impacts on individual mode choice: An empirical study of the Houston-Galveston metropolitan area. International Journal of Sustainable Transportation, null-null. doi: 10.1080/15568318.2012.716142

Nankervis, M. (1999). The effect of weather and climate on bicycle commuting. Transportation Research Part A: Policy and Practice, 33(6), 417-431. doi: http://dx.doi.org/10.1016/S0965-8564(98)00022-6

Nkurunziza, A., Zuidgeest, M., \& Van Maarseveen, M. (2012). Identifying potential cycling market segments in Dar-es-Salaam, Tanzania. Habitat International, 36(1), 78-84. doi: http://dx.doi.org/10.1016/j.habitatint.2011.06.002

Panter, J., Jones, A., van Sluijs, E., \& Griffin, S. (2010). Attitudes, social support and environmental perceptions as predictors of active commuting behaviour in school children. [Research Support, Non-U.S. Gov't]. Journal of epidemiology and community health, 64(1), 41-48. doi: 10.1136/jech.2009.086918

Reynolds, C., Winters, M., Ries, F., \& Gouge, B. (2010). Active transportation in urban areas: Exploring health benefits and risks. National Collaboration Centre for Environmental Health, 1-15.

Richardson, A. (2006). Estimating Bicycle Usage on a National Cycle Network. Transportation Research Record: Journal of the Transportation Research Board(1982), 166-173. doi: $10.3141 / 1982-22$

Statistics Canada. (2006). Canadian Census. 
Statistics Canada. (2011). Canadian Census.

Stinson, M., \& Bhat, C. (2004). Frequency of bicycle commuting: Internet-based survey analysis. Transportation Research Record(1878), 122-130. doi: 10.3141/1878-15

Tal, G., \& Handy, S. (2008). Children's biking for non-school purposes: Getting to soccer games in Davis, CA. Transportation Research Record(2074), 40-45.

Underwood, S., \& Handy, S. (2012). Adolescent attitudes toward active transportation: Bicycling in youth in retrospect from adulthood: University of California, California.

van Exel, N., \& Rietveld, P. (2010). Perceptions of public transport travel time and their effect on choice-sets among car drivers. Journal of Transport and Land Use, 2(3), 75-86.

van Lierop, D., Grimsrud, M., \& El-Geneidy, A. (2013). Breaking into bicycle theft: Insights from Montreal, Canada. Internation Journal of Sustainable Transportation(Accepted).

Vélo Québec. (2010). L'état du vélo au Québec en 2010: zoom sur Montréal. In V. Québec (Ed.), L'état du vélo au Québec (pp. 28). Montréal: Vélo Québec.

Ville de Montréal. (2008). Réinventer Montréal: Plan de transport 2008. Montréal.

Wegman, F., Zhand, F., \& Dijkstrat, A. (2012). How to make more cycling good for road safety. Accident Analysis and Prevention, 44(1), 19-29.

Woodcock, J., Edwards, P., Tonne, C., Armstrong, B., Ashiru, O., Banister, D., . . Roberts, I. (2009). Public health benefits of strategies to reduce greenhouse-gas emissions: Urban land transport. www.thelancet.com, 374(9705), 1930-1943. 